1 Universidade Federal do Paraná (UFPR) - Curitiba (PR), Brasil.

silviajaquel@gmail.com

2 Universidade Federal do Paraná (UFPR) - Curitiba (PR), Brasil.

larocca_m@terra.com.br

3 Universidade Federal do Paraná (UFPR) - Curitiba (PR), Brasil.

mnolasco@terra.com.br

4 Universidade Federal do Paraná (UFPR) - Curitiba (PR), Brasil.

sandramalessi@gmail.com

\section{A realidade objetiva das Doenças e Agravos Não Transmissíveis na enfermagem}

\author{
The objective reality of Non-communicable Diseases and Injuries in \\ nursing
}

Silvia Jaqueline Pereira de Souza', Liliana Müller Larocca², Maria Marta Nolasco Chaves², Sandra

Mara Alessi4

RESUMO Pesquisa qualitativa, tipo estudo de caso, fundamentada na Teoria da Intervenção Práxica da Enfermagem em Saúde Coletiva, com objetivo de conhecer a realidade objetiva das Doenças e Agravos Não Transmissíveis que acometem trabalhadores de enfermagem. Foram identificados nos discursos dos sujeitos dois gatilhos para o aparecimento de desgastes: a sobrecarga do trabalho e a deficiência de recursos humanos. O estudo forneceu subsídios à instituição para a elaboração de intervenções que melhorem as condições de saúde de seus trabalhadores por meio da reflexão da prática profissional em enfermagem.

PALAVRAS-CHAVE Saúde do trabalhador; Enfermagem; Saúde pública.

ABSTRACT Qualitative research, sort of case study, founded on the Theory of Praxis Intervention in Collective Health Nursing, with the aim of knowing the objective reality of non-communicable diseases that affect nursing workers. Two triggers for the emergence of distress were identified in the participants' speeches: workload and staff shortage. The study provided subsidies for the institution to elaborate interventions which improve workers' health conditions by means of reflection of the nursing professional practice.

KEYWORDS Occupational health; Nursing; Public health. 


\section{Introdução}

A saúde do trabalhador, no Brasil, vem aumentando sua visibilidade no contexto social desde o Movimento de Reforma Sanitária, em 1980. A partir de então, inúmeras discussões e conferências foram realizadas visando à sua consolidação. Em 1988, com a Constituição e, logo após, a promulgação da Lei Orgânica da Saúde (Lei $\left.\mathrm{n}^{\circ} 8.080 / 1990\right)$, iniciou-se um amplo processo que se solidificou em 2012, quando o Ministério da Saúde, por meio da Portaria GM/MS $\mathrm{n}^{\circ} 1.823$, estabeleceu a Política Nacional de Saúde do Trabalhador e da Trabalhadora (BRASIL, 2012).

Outro tema que ganhou espaço nas discussões e na promulgação de políticas públicas está relacionado às Doenças e Agravos Não Transmissíveis (Dant), as quais, devido às intensas modificações ocorridas nos perfis demográfico e epidemiológico da população brasileira em geral, são responsáveis, segundo dados do Ministério da Saúde, por $72 \%$ das taxas de mortalidade registradas no País (BRASIL, 2011).

Trazendo o tema à realidade da presente pesquisa, tese desenvolvida no ano de 2012, apontou para as Dant 'câncer/suicídio' como dois grandes problemas de mortalidade entre enfermeiros. Em outro estudo, os resultados apontam para a enfermagem como sendo a quarta profissão mais estressante do setor público, tendo como fatores de risco as doenças cardiovasculares, o estresse, a hipertensão arterial e a obesidade. A enfermagem cumpre um dos mais importantes papéis na sociedade, posto que administra, diariamente, a tensão emocional do cuidado direto às pessoas doentes, convivendo com duplas jornadas de trabalho, salários irrisórios e atividades insalubres (KARINO, 2012; TEIXEIRA; MANTOVANI, 2009).

O contato com trabalhadores de enfermagem gerou o seguinte questionamento: seria a realidade objetiva do trabalho um determinante para o desenvolvimento de Dant entre os profissionais de enfermagem de um hospital de ensino de Curitiba?

Entendemos que o processo saúde-doença é histórico e socialmente determinado, pois as diferentes mudanças que ocorrem em uma determinada sociedade, em um certo momento histórico, são capazes de promover transformações na forma de adoecer e morrer dos indivíduos e grupos populacionais, assim como interferem diretamente na composição e organização/estruturação do sistema de saúde.

Desta forma, o presente estudo tem como objetivo conhecer a realidade objetiva das Dant que acometem trabalhadores de enfermagem atuantes na Unidade Gerencial de um hospital de ensino do estado do Paraná. Acredita-se ser imprescindível conhecer o processo de trabalho da enfermagem no cenário proposto, identificando e intervindo nas contradições que levam os profissionais de enfermagem ao adoecimento.

\section{Método}

Pesquisa de natureza qualitativa, que, de acordo com os fins, é descritiva e, quanto aos meios, um estudo de caso (TOBAR; YALOUR, 2001). Como referencial metodológico, foi utilizada a Teoria da Intervenção Práxica da Enfermagem em Saúde Coletiva (Tipesc) (EGRY, 1996). A Tipesc propõe cinco etapas: conhecimento da realidade objetiva; interpretação da realidade objetiva; construção de projeto de intervenção na realidade objetiva; intervenção na realidade objetiva; reinterpretacão da realidade objetiva. Dessas, foram realizadas as duas primeiras, respectivamente: o conhecimento e a interpretação da realidade objetiva.

$O$ referencial metodológico adotado permitiu reconhecer a realidade por meio das dimensões estrutural, particular e singular (reconhecidas como categorias analíticas). A 'dimensão estrutural' abrange os processos de crescimento da capacidade produtiva e 
das relações de produção, concepções econômicas e político-ideológicas, em certo contexto. A 'dimensão particular' compreende demandas de reprodução social (no processo de trabalho, a produção e a reprodução não podem ser adotadas separadamente, pois, olhando de modo interligado, todo processo de produção social é, concomitantemente, um processo de reprodução), conforme a classe social na qual o trabalhador se insere, e ocasiona os processos de saúde-doença, devido ao período produtivo/reprodutivo que origina padrões de proteção e desgaste. E, por último, a 'dimensão singular', formada pelos processos que diretamente levam o indivíduo a adoecer e morrer, ou que podem consolidar o aprimoramento da sua saúde, considerando-se que esses ocorrem de acordo com a participação do indivíduo na organização social (EGRY, 1996).

Como campo de pesquisa, optamos pela Unidade Gerencial Cardiovascular e de Pneumologia integrante de um hospital público de ensino do Paraná. Essa Unidade Gerencial é uma das 23 unidades implantadas. Entre elas, 6 são unidades administrativas e 14 assistenciais, sendo estas últimas subordinadas à Direção de Assistência. No organograma do hospital ainda existem 6 Direções além da Direção de Assistência. São elas: Direção Geral, Direção Administrativa, Direção de Corpo Clínico, Direção de Ensino e Pesquisa, Direção Financeira e Direção de Enfermagem. Esta última foi reativada após a implantação das Unidades Gerenciais e, hoje, é responsável por toda a equipe e assistência de enfermagem do hospital. As Unidades Gerenciais têm como finalidade operacionalizar e integrar as ações de assistência, ensino, pesquisa e extensão desenvolvidas no hospital, independentemente de serem administrativas e/ou assistenciais (UFPR, 2012).

Participaram do estudo 10 informantes-chave. Utilizamos uma amostra intencional, incluindo: enfermeiros, técnicos e auxiliares de enfermagem e profissionais administrativos, selecionados pelo conhecimento que possuíam sobre o cenário investigado, o qual é responsável por prestar assistência específica a usuários do SUS nas áreas de cardiologia clínica, pneumologia, cirurgia cardiovascular, torácica e vascular periférica, ambulatórios e unidades de internação (UFPR, 2012).

Atualmente, na Unidade Gerencial Cardiovascular e de Pneumologia (UCP), trabalham 52 auxiliares de enfermagem, 23 técnicos em enfermagem, 13 enfermeiros, 46 médicos e 12 profissionais administrativos. A UCP tem três características: internação, ambulatórios e exames, que são serviços distintos dentro de uma mesma unidade. A unidade Gerencial é composta por 7 setores: métodos cardiológicos, laboratório de função pulmonar, laboratório de hemodinâmica, unidade de internação de cardiologia, unidade de internação de pneumologia, unidade de internação vascular, centro de terapia intensiva cardiológico (UFPR, 2012).

A disponibilidade e a aquiescência foram condições para que os trabalhadores de saúde do cenário estudado participassem do estudo, além dos demais critérios para inclusão, que foram: serem maiores de idade, independentemente de sexo, formação, etnia, procedência ou grupo social. Os critérios de exclusão foram: não fazer parte do quadro funcional da Unidade Gerencial Cardiovascular e de Pneumologia ou se recusar a participar do estudo.

O recrutamento dos informantes-chave ocorreu por contato pessoal, conforme condições constantes no Termo de Consentimento Livre e Esclarecido (TCLE). A coleta deu-se por meio de entrevista aberta, individual, no período de janeiro a fevereiro de 2013, em horários e locais previamente determinados pelos participantes. O estudo foi aprovado pelo Comitê de Ética em Pesquisa da instituição, sob o número CAAE 02193112.2.0000.0096.

As falas foram classificadas e agrupadas de acordo com as categorias dimensionais e 
analíticas, e, posteriormente, a organização deu lugar ao agrupamento de fragmentos de discursos por categorias e subcategorias. Os sujeitos foram codificados como InformanteChave (IC) e seguidos por número ordinal, de 01 a 10, de modo que as codificações se dispuseram entre IC01 e IC10. O objetivo de utilizar uma codificação foi a não identificação dos participantes, sem prejuízos à identificação dos emissores das falas.

\section{Resultados e discussão}

Para conhecer a realidade objetiva, foram descritas as dimensões, sendo a estrutural considerada por meio dos amparos jurídico e político ao trabalhador em caso de adoecimento e acidentes, assim como a política de contratação de pessoal para desenvolver prevenção de agravos e a integralidade na atenção à saúde do trabalhador. A dimensão particular foi compreendida como o trabalho da equipe de enfermagem no hospital. Para compreendê-la, subdividiu-se essa dimensão da realidade nos seguintes aspectos: mês típico de trabalho; conflito no trabalho; organização do trabalho da enfermagem; sobrecarga de trabalho; recursos humanos para o trabalho; faltas no trabalho, licenças para tratamento de saúde e atestados médicos; absenteísmo no trabalho; qualidade da assistência de enfermagem. $\mathrm{Na}$ dimensão singular, foram reconhecidas as referências às Dant nos trabalhadores estudados. No inter-relacionamento das categorias dimensionais, reconheceram-se as diferentes partes do fenômeno estudado, o que possibilitou a reflexão sobre a relação dialética entre as mesmas e o todo (GARCIA; EGRY, 2010).

\section{Dimensão estrutural}

Conforme apontado anteriormente, a dimensão estrutural, neste estudo, compreende os processos jurídico-legais relativos à saúde do trabalhador no Brasil, assim como as políticas e leis afetas à promoção da saúde, prevenção de agravos e a integralidade na atenção à saúde do trabalhador.

De acordo com a Constituição Federal de 1988, a conformação da saúde do trabalhador é colocada como competência do SUS, que assegura, em seu artigo 198, que "[...] as ações e serviços de saúde integram uma rede regionalizada e hierarquizada [...]" (BRASIL, 1986).

Analisando a fala dos informantes, observaram-se condições do processo de trabalho que reforçam as suas condições precárias, como, por exemplo, a sobrecarga de trabalho que incide sobre o trabalhador:

[...] na nossa unidade, por falta do funcionário, existe muito $A P H$ [Adicional de Plantão Hospitalar] [...] as pessoas se desgastam muito pelo valor econômico que isso gera [...] dobram demais, fazem 48 horas na semana, doze horas todo dia [...] ficam muito cansadas [...]. (ICO1).

Em fevereiro de 2009, foi promulgada a Lei $\mathrm{n}^{\mathrm{o}} 11.907$, a qual, entre outros assuntos relacionados aos salários de servidores federais, instituiu o Adicional por Plantão Hospitalar (APH): um valor suplementar pago aos servidores que desempenham regime de plantões em áreas que necessitam funcionar ininterruptamente. Ele só pode ser realizado além da carga horária semanal e no limite de 24 horas por semana (BRASIL, 2010).

Nesta questão ressaltamos o dimensionamento de pessoal. O adicional de plantão hospitalar surgiu como solução para a discrepância na força de trabalho, e a princípio funcionou desta forma, porém as situações relatadas permitem afirmar que a proposta do APH veio para explorar a força de trabalho empregada. Ela não permite uma discussão sobre o porquê de o trabalhador estar sobrecarregado e submetido às condições estruturais vigentes, o que o leva a um desgaste físico e, consequentemente, emocional. 


\section{Dimensão particular}

Uma vez que a dimensão particular abrange os processos de reprodução social, com ênfase no processo de trabalho, destacam-se: a jornada, a intensificação e a organização do trabalho, bem como pontos referentes a faltas, licenças para tratamento de saúde e atestados médicos, recursos humanos e conflitos.

Quando solicitado aos informantes-chave que descrevessem um mês típico do seu trabalho, entre os enfermeiros, houve destaque para as atividades administrativas: “[...] muitas vezes, tenho reuniões [...] cuidar de ficha funcional [...] organizar pastas de Planos Operacionais Padrão [...]" (IC06); "[...] diariamente, eu tenho a função de ver o quadro de funcionários [...] estamos incluídos em comissões de estruturação [...]" (IC08).

Estudos apontam para um predomínio das atividades administrativas e gerencias sobre as assistenciais na prática do enfermeiro, pois este tem seu tempo tomado, em grande parte ou na totalidade, pelo serviço administrativo, delegando a assistência direta ao usuário aos profissionais de nível médio, os quais estão sob sua supervisão (HAUSMANN; PEDUZZI, 2009). A realidade explicitada vem corroborar o apontado pela literatura, pois constata-se tal ocorrência devido ao grande volume de registros e relatórios institucionais, bem como ao menor número de enfermeiros na composição das equipes.

No Brasil, a Lei do exercício profissional traz, em seu Art. 11, uma descrição do que é privativo ao enfermeiro: a organização e a coordenação dos serviços de assistência e das atividades técnicas e auxiliares prestadas nesses serviços (BRASIL, 1986). Apesar do respaldo legal, observam-se conflitos com relação à práxis do trabalho em enfermagem.

O conceito 'conflito' esteve presente na fala dos informantes: "[...] conflito [riso] é todo dia, quase! [...] As pessoas têm suas exigências... não entendem a questão do local de trabalho, muito pouco veem a realidade de trabalho" (IC02). "[...] o espaço hospitalar é um espaço de conflito, é um espaço de busca de poder [...]. Nós fazemos parte de uma equipe multiprofissional [...]”" (IC08).

Conflitos são discordâncias internas, resultantes da diferença de pensamento e de ideias de profissionais que trabalham no mesmo ambiente, em que, muitas vezes, estão envolvidas, diretamente, questões de poder. Faz-se necessário interpretar o conflito pela ótica de todos os agentes envolvidos, para decodificá-lo e buscar resolvê-lo, também em sua perspectiva dialética (KURCGANT, 2010).

Para Foucault (2001), o poder atua como ferramenta de diálogo entre sujeitos de uma coletividade. É por meio dele que as pessoas são impulsionadas a conduzir suas ações, com o intuito não apenas de admoestar, mas, também, de regularizar. Enquanto elemento, o poder tem a capacidade de explicar como se produz o conhecimento e como se articula. $\mathrm{O}$ autor ressalta, ainda, que não existe sociedade livre do poder, e que os indivíduos são resultados dessas relações.

Espera-se que o enfermeiro seja agente mediador das situações de conflito dentro da equipe. Obviamente, isso ocorrerá perante a postura adotada ante a situação, bem como a estratégia que utilizará para gerenciar o fato e buscar a melhor solução para o mesmo.

Com relação à organização do trabalho da enfermagem, embora todos façam parte da mesma unidade gerencial, não existe um padrão a ser seguido. Cada serviço se organiza de forma diferenciada e pela conveniência, como se evidencia nas falas a seguir: “[...]. Os métodos cardiológicos são divididos em quatro setores [...]. Cada setor funciona de uma forma independente, cada um tem sua peculiaridade e a sua equipe, tanto médica como de enfermagem" (IC02). "[...] nós temos uma enfermeira de manhã e uma à tarde. Percebemos bem a diferença do processo de trabalho de cada uma delas" (IC07). 
$\mathrm{Na}$ assistência de enfermagem, o processo de trabalho é muito complexo, corroborando a literatura, que afirma que planejamento e organização possibilitam ao enfermeiro exercer suas atividades de forma coerente e responsável (KURCGANT, 2010).

Em contraposição, Almeida e Rocha (1997) destacam que organizar o trabalho de enfermagem em tarefas, direcionando a execução de uma escala de trabalho, causa um adestramento, o que possibilita o controle social desse trabalhador por meio de uma divisão técnica de trabalho.

Ressalta-se, ainda hoje, a existência de grande resistência por parte de auxiliares e técnicos em aceitar o comando do enfermeiro. Em muitas situações, ocorre uma distorção do cargo exercido por esse profissional: ou ele é visto como intransigente, e colocado à margem dos demais membros da equipe de enfermagem, ou, quando busca se aproximar da equipe, com frequência, é acolhido como 'amigo', o que pode ocasionar algumas dificuldades nas tomadas de decisão inerentes ao cargo de chefia e supervisão, indo contra o interesse do grupo sob o seu comando.

A sobrecarga de trabalho também teve destaque: "[...] temos uma demanda grande de trabalho [...] temos poucos funcionários [...] achamos que não iremos dar conta do serviço [...] é muito estressante [...]" (IC04). "O hospital tenta jogar o máximo de atribuições [...], cada vez mais eles estão descentralizando e jogando para a gente, é muita coisa, é muito serviço [...]" (IC10).

A literatura ressalta que ter uma equipe de enfermagem presente 24 horas por dia nas instituições hospitalares já caracteriza intensificação do trabalho. Somada a essa situação (e a agravando), há a escassez de profissionais, o que torna o trabalho acelerado, intenso e desgastante. Trabalhar com um número de profissionais reduzido influencia a desqualificação da assistência prestada por eles. A realidade apontada demonstra que os trabalhadores de enfermagem acabam trabalhando mais de 44 horas semanais para cobrir ausências, férias, faltas, licenças para tratamento de saúde e atestados médicos, como também em decorrência da má remuneração que recebem. Em muitas instituições, essas horas trabalhadas compõem bancos de horas que são gozadas de acordo com a conveniência das instituições, e, por diversas vezes, devido à escassez de profissionais, nem são desfrutadas (FELLI, 2012).

Juntamente com o tema da sobrecarga referida dos informantes-chave, evidenciou-se a deficiência qualitativa e quantitativa dos recursos humanos. "[...] todos os dias eu trabalho com, no mínimo, duas pessoas fazendo horas extras, se não houver falta, atestado ou férias [...]" (IC01). "[...] me sinto sobrecarregado [...] faço quase outra escala no período contrário ao meu horário [...]" (IC04). "Foi feito um redimensionamento ano passado [...] não é o ideal. Se tivéssemos tudo conforme manda o Coren, seria um problema a menos para resolver" (IC06).

$\mathrm{O}$ dimensionamento de pessoal em enfermagem tem recebido bastante atenção, principalmente das instituições de saúde, uma vez que, nos dias de hoje, a saúde cada vez mais é vista como mercadoria. O capitalismo gira em torno da lei de oferta e procura. Se, por um lado, tem-se a necessidade de ampliar a oferta dos serviços de saúde, por outro, existe a contenção de custos, o que acarreta a cobrança de melhor qualidade e eficácia dos serviços prestados pelos profissionais do setor.

O Conselho Federal de Enfermagem, no ano de 2004, estabeleceu parâmetros para o dimensionamento do quadro de profissionais de enfermagem, com base no perfil de dependência dos pacientes atendidos nas unidades hospitalares, bem como a quantidade de horas que o profissional necessita desenvolver para atendê-los (COFEN, 2004).

Essa proporção constitui o recurso mais desafiante para as instituições de saúde, pois todo o processo de trabalho em saúde é diretamente dependente das pessoas que o desenvolvem. Em economia de Estado 
mínimo, é provável que o setor administrativo dessas instituições seja constantemente pressionado à redução dos recursos humanos, mais uma vez, pensando na questão do lucro, como mencionado anteriormente (KURCGANT, 2010). No entanto, essa conjuntura deficitária de gestão de pessoas vem gerando múltiplos problemas para a saúde dos trabalhadores, como: sobrecarga de trabalho, estresse, fadiga, desmotivação e, com isso, o aumento das taxas de absenteísmo, faltas e atestados médicos.

Emergiu nas falas dos informantes-chave a temática sobre o que mais os incomodava no seu ambiente de trabalho, e o problema com os recursos humanos voltou a aparecer:

[...] às vezes, você quer ficar um final de semana em casa [...], faz algum tempo que eu não tenho um sábado e um domingo em casa. Ou eu estou de plantão no sábado ou no domingo, desde a metade do ano passado que eu não consigo [...] a minha escala é quase que dobrada. Geralmente, meus plantões são de 24 horas [...]. (ICO3).

O absenteísmo, as faltas, as licenças para tratamento de saúde e os atestados médicos foram recorrentes nas falas dos informantes-chave, associados às questões de recursos humanos deficitários e da sobrecarga de trabalho.

Os funcionários estão envelhecendo, são cansados por causa da sobrecarga, porque não tem como suprir essa falta de funcionário, daí, tem o APH, todo mundo faz [...] é difícil, eu tenho certeza que ausência, atestado, falta é tudo cansaço e idade [...] não tem jovem trabalhando aqui [...] acho que esse é o maior problema do hospital. (IC10).

A sobrecarga de trabalho leva o trabalhador ao adoecimento. A fala do IC10 vem ao encontro do que aponta Felli (2012). A autora afirma que o adoecimento, como consequência de uma jornada de trabalho exaustiva e intensa, é frequente na enfermagem. No seu estudo, a autora aponta que trabalhadores de enfermagem, com idade média de 40 anos, já trabalham com algum tipo de dor, fadiga e desgaste, destacando que, frequentemente, um profissional só busca o afastamento de suas funções quando não possui alternativa.

Em virtude das condições de trabalho adversas, os trabalhadores podem recorrer a meios para compensar o sofrimento, adotando posturas defensivas. Por outro lado, a enfermagem é a maior força de trabalho das instituições hospitalares e, devido a isso, acaba integrando a categoria de profissionais que mais sofre com condições insalubres de trabalho. Nota-se que, rotineiramente, os hospitais não preveem cobertura para atestados médicos e absenteísmos, o que gera desgaste e sofrimento a todos os envolvidos no processo (COSTA; VIEIRA; SENA, 2009).

A qualidade da assistência de enfermagem prestada é prejudicada com o processo de trabalho aqui exposto. Alguns dos informantes mencionaram no seu discurso uma preocupação com o tipo de assistência que estão prestando aos seus pacientes.

[...] tenho uma equipe bastante cansada, fazendo um ritmo bastante forte [...]. Já não tem mais tanta intimidade com o que faz [...], já não consegue interagir muito com o cliente [...]. A qualidade da assistência na minha unidade não é um ponto que possa se destacar, embora os funcionários [...] tenham um conhecimento técnico muito grande [...] na tomada de decisão, são muito efetivos, mas deixaram para trás o que é da enfermagem: cuidado direto com o paciente. (ICO1).

No mundo do trabalho, cada vez mais, procura-se e cobra-se qualidade nos serviços. Na saúde, esse panorama não é diferente. $\mathrm{O}$ mercado favorece empresas que ofertam melhores serviços a menores custos e condena as que não alcançam esse patamar. Os usuários estão mais conscientes dos seus direitos, exigindo atendimento 
com dignidade e ética por parte dos profissionais de saúde. Acredita-se que a enfermagem tem o compromisso de prestar o cuidado com qualidade, mas, para isso, fazem-se necessárias condições dignas para o desenvolvimento do trabalho. A assistência de enfermagem adequada depende de inúmeros processos que se inter-relacionam, entre eles: número de profissionais adequado, estrutura e organização das instituições de saúde para proporcionar condições qualificadas à assistência. Não se pode deixar de lado a necessidade de avaliações frequentes, a fim de contribuir para a melhoria dos serviços de saúde prestados à população (D'INNOCENZO; ADAMI; CUNHA, 2006).

\section{Dimensão singular}

Esta dimensão envolve as ações que visivelmente levaram os indivíduos a adoecer, morrer, ou aprimorar seus processos protetores. Compreende, também, métodos de trabalhos específicos dos setores assistenciais nos serviços (EGRY, 1996).

Ao questionar os informantes-chave sobre as Dant que acontecem com os profissionais de enfermagem no cenário estudado, observou-se o desconhecimento do termo pelos entrevistados. Assim sendo, foi realizada uma breve explanação sobre o assunto, obtendo-se os seguintes discursos - curiosamente, os informantes falaram de outros profissionais, não trazendo a questão para si:

Olha, todos tomam algum medicamento controlado [...] eu acho que a grande maioria está tomando algum antidepressivo, algum tranquilizante, alguma coisa assim [...]. De certa maneira, tem uma doença crônica $[\ldots]$, tem pessoas com hipertensão, problemas renais [...]. (ICO2).

"Na hemodinâmica, houve uma época que, de dez funcionários, quatro tinham algum tipo de câncer. É um índice alto para qualquer lugar [...]" (IC03).
[...] agora, tem uma servidora que está afastada. Ela é portadora de doença crônica, diabetes. Houve um afastamento, também, de 40 dias, de outra por transtorno mental. Existem outras pessoas, também, que fazem acompanhamento [...]. (ICO8).

Nota-se nos discursos que, embora atendam e prestem cuidado de enfermagem a pessoas doentes, os trabalhadores de enfermagem, frequentemente, acabam por negligenciar seu cuidado pessoal. Esquecem que compartilham o mesmo perfil de adoecimento da população em geral, com um agravante: estão expostos ao ambiente insalubre cotidianamente, o que potencializa o seu desgaste.

Estudos realizados em hospitais públicos e universitários evidenciam e ratificam que a enfermagem presta cuidado ininterrupto, trabalha em turnos, como dito anteriormente, e, em muitas situações, em dupla jornada. Seus trabalhadores são constantemente expostos a diferentes cargas de trabalho, desenvolvendo processos protetores e de desgaste (FELLI, 2012).

As Dant são um problema de saúde pública. Estudos demonstram que análises de sangue de trabalhadores de um hospital universitário apresentaram alteração em $60 \%$ dos resultados, o que corrobora a comprovação do grau de prevalência das Dant nesses ambientes de trabalho (TEIXEIRA; MANTOVANI, 2009).

Outro estudo realizado recentemente denuncia câncer e suicídio como principais causas de morte entre enfermeiros. O câncer, mais relacionado às altas cargas de horas trabalhadas e à exposição a agentes físicos e químicos; o suicídio apontando para sofrimento, estresse e angústia (KARINO, 2012). Na fala de alguns informantes, constatam-se indícios que referendam os achados do estudo citado, conforme a fala a seguir.

[...] A radiação [...], a gente sabe que é um risco, que, se for prejudicar o funcionário [...], é em 
longo prazo, 20, 30, 40 anos; [...] A radiação me preocupa porque a gente acaba sendo bastante exposto, porque os exames são muito prolongados, a gente fica muito tempo em sala, não tem como rodar. Esse mês mesmo o dosímetro veio alto [...]. (ICO7).

Compreende-se o sentimento de medo numa conexão entre as dimensões particular e singular. Mesmo experimentando esse anseio, os trabalhadores se arriscam, pois necessitam do emprego. Esses indivíduos desenvolvem defesas, meios de compensar esse medo, transformando-se em figuras resistentes, com posturas defensivas, por vezes, levando à indiferença (DEJOURS, 1992). Quando esse trabalhador distorce sua autodefesa, pode suscitar atitudes de descaso ou negligência com relação à sua própria saúde (GESSNER ET AL., 2013).

Analisando a dimensão singular nos trechos destacados, ficaram evidentes os processos que induzem ao adoecimento dos profissionais de enfermagem, mas também deve-se levar em conta o seu modo de viver, pois, enquanto indivíduos, estão inseridos em uma classe social, e o modo como reproduzem seu cotidiano familiar e comunitário também interfere na sua condição de saúde ou doença. Porém, conforme foi apontado pelos entrevistados, informantes-chave, o trabalho se constitui em uma significativa parcela do seu cotidiano, visto que há uma carga horária a ser cumprida, seja ela no horário pelo qual são legalmente responsáveis, como também naqueles nos quais têm se disposto a trabalhar para cobrir a falta de pessoal. Assim, o trabalho tem sido um processo de desgaste para esses trabalhadores da enfermagem.

\section{Considerações finais}

Os fenômenos das mudanças sociais no mundo respondem por grandes transformações políticas e econômicas, as quais repercutem diretamente no mundo do trabalho. As organizações que prestam serviços de saúde tornaram-se exigentes quanto à característica dos serviços prestados, obrigando o trabalhador a, contraditoriamente, adaptar-se para manter sua fonte de renda, contrabalanceando a manutenção da qualidade da assistência de enfermagem que presta aos usuários desses serviços.

Este estudo permitiu constatar que há deficiências com relação à saúde do trabalhador no serviço de saúde investigado. Um aspecto muito destacado nos depoimentos dos informantes-chave foi a questão do dimensionamento de recursos humanos para a assistência à saúde de alta complexidade que é prestada. Essa é uma realidade encontrada tanto em serviços do setor privado quanto do público. Relação desigual que atende à pressão do mercado, o qual privilegia a prestação de serviços de custo baixo, sem a preocupação com a qualidade e a complexidade da assistência à saúde que se oferece.

Nos discursos, a idade avançada dos trabalhadores foi mencionada. É tendência dos profissionais ligados às instituições públicas, devido à estabilidade do vínculo estatutário, permanecer por longo tempo e, às vezes, toda vida produtiva no mesmo cenário, até que possam se aposentar. Nesse setor, a reposição de profissionais exige um processo seletivo que é longo, embora, na atualidade, já exista uma tendência de que essa reposição ocorra mais rapidamente. Contudo, o preço a pagar é a flexibilização da contratação do trabalhador, terceirização ou contrato por meio da Consolidação das Leis Trabalhistas (CLT), o que tornará inviável a carreira pública no setor.

Nas falas, revela-se que o Estado, com a implantação do $\mathrm{APH}$, buscou uma alternativa para manter o funcionamento dos 
serviços de saúde, mas não deu relevância ao fato de que, embora a recompensa financeira seja atraente para o trabalhador da equipe de enfermagem, existem limitações para tal. Entre elas, destacam-se os desgastes físicos e psicológicos, o que leva, posteriormente, ao aumento dos atestados médicos e das licenças para tratamento de saúde.

Identificaram-se nos discursos dos sujeitos envolvidos dois gatilhos para o aparecimento de desgastes: a sobrecarga do trabalho e a deficiência numérica de profissionais de enfermagem. Logo, não se pode atribuir o absenteísmo exclusivamente à decisão pessoal do trabalhador. Faz-se necessário observar as condições de trabalho oferecidas e os processos de trabalho desenvolvidos no cenário da pesquisa, pois os profissionais da equipe de enfermagem envolvidos na assistência aos usuários do serviço são diariamente expostos a diversos processos de desgaste, resultantes das complexas atividades desenvolvidas, as quais podem gerar adoecimentos e sofrimentos. Essa exposição constante, por vezes não percebida pelo próprio trabalhador, pode gerar diferentes sinais e sintomas, os quais, muitas vezes, não permitem estabelecer os nexos causais com o trabalho exercido.

Por fim, acredita-se que a experiência de aproximação e reconhecimento da realidade objetiva desses profissionais permitiu a constatação de que as condições de trabalho, tal como aqui foram exploradas, têm adoecido os trabalhadores da enfermagem, e que essa é uma situação compartilhada com os demais profissionais da saúde. Assim, torna-se imprescindível uma intervenção para modificar a realidade explicitada.

\section{Referências}

ALMEIDA, M. C. P.; ROCHA, S. M. O Trabalho de Enfermagem. São Paulo: Cortez, 1997. 296 p.

BRASIL. Decreto 7.186/10, de 27 de maio de 2010. Regulamenta os Arts. 298 a 307 da Lei No 11.907, de 2 de fevereiro de 2009, que tratam do adicional por plantão hospitalar - APH. Diário oficial [da] União. Brasília, DF, 28 maio 2010. Disponível em: <http://www.planejamento.gov.br $/$ noticia.asp? $\mathrm{p}=$ not $\& \operatorname{cod}=6218 \& \mathrm{cat}=26 \& \mathrm{~s}$ ec $=11>$. Acesso em: 10 abr. 2013.

. Lei no 7.498, de 25 de Junho de 1986. Dispõe sobre a regulamentação do exercício da enfermagem e dá outras providências. Diário Oficial [da] União. Brasília, DF, 26 jun. 1986. Disponível em: < http://www.planalto.gov. br/ccivil_03/leis/17498.htm>. Acesso em: 20 jan. 2013.

\footnotetext{
. Ministério da Saúde. Portal da Saúde. Sobre

a Saúde do Trabalhador. Disponível em: <http:// Portal.Saude.Gov.Br/Portal/Saude/Visualizar_Texto. Cfm?Idtxt=30426\&Janela=1>. Acesso em: 5 dez. 2012.

. Ministério da Saúde. Secretaria de Vigilância em Saúde. Departamento de Análise de Situação de Saúde. Plano de ações estratégicas para o enfrentamento das doenças crônicas não transmissíveis (dcnt) no Brasil, 2011-2022. Brasília, DF: Ministério da Saúde, 2011. Disponível em: <http://portal.saude.gov.br/portal/ arquivos/pdf/plano_acoes_estrategicas20x20_25julho. pdf.>. Acesso em: 11 ago. 2012.
}

CONSELHO FEDERAL DE ENFERMAGEM

(COFEN). Resolução Cofen - no 293/2004. Fixa e 
estabelece parâmetros para dimensionamento do quadro de profissionais de enfermagem nas unidades assistenciais das instituições de saúde e assemelhados. Rio de Janeiro, 2004. Disponível em: <http://novo.portalcofen.gov.br/resoluo-cofen-2932004_4329.html $>$. Acesso em: 15 abr. 2013.

\section{COSTA, F. M.; VIEIRA, M. A.; SENA, R.}

R. Absenteísmo relacionado à doenças entre membros da equipe de enfermagem de um hospital escola. Rev. Bras. Enferm.[Online]. v. 62, n. 1, p. 38-44, 2009. Disponível em: $<$ http://www.scielo.br/pdf/reben/ v62nl/06.pdf >. Acesso em: 12 maio 2013.

D'INNOCENZO, M.; ADAMI, N. P.; CUNHA, I. C. K. O. O movimento pela qualidade nos serviços de saúde e enfermagem. Rev. Bras. Enferm. [Online]. v. 59, n. 1, p. 84-88, 2006. Disponível em: <http://www.scielo.br/pdf/ reben/v59nl/al6v59nl.pdf>. Acesso em: 12 maio 2013.

DEJOURS, C. A loucura do trabalho: estudo de psicopatologia do trabalho. 5 ed. Ampliada. São Paulo: Cortez Editora, 1992.

EGRY, E. Y. Saúde coletiva: construindo um novo método em enfermagem. São Paulo: Ícone, 1996.

FELLI, V. E. A. Condições de trabalho de enfermagem e adoecimento: motivos para a redução da jornada de trabalho para 30 horas. Enfermagem em Foco, Brasília, DF, n. 3, p. 178-181, 2012. Disponível em: <http://revista. cofen.gov.br/index.php/enfermagem/article/viewFile/379/170 >. Acesso em: 12 ago. 2012.

FOUCAULT, M. Ditos e escritos. Paris: Quarto Gallimard, 2001.

GARCIA, T. R.; EGRY, E. Y. Integralidade da atenção no SUS e sistematização de enfermagem. Porto Alegre: Artmed, 2010. Disponível em: <http://books.google.com. br/books?id=-qrn9xw_0pmc\&printsec=frontcover\&hl= pt-br\#v=onepage\&q\&f=false>. Acesso: 12 maio 2013.

GESSNER, R. et al. As notificações de acidentes de trabalho com material biológico em um hospital de ensino de Curitiba/PR. Saúde debate [online]. v. 37, n. 99, p. 619-627, 2013. Disponível em: <http://www. scielo.br/pdf/sdeb/v37n99/a09v37n99.pdf >. Acesso em: 10 jan. 2014

HAUSMANN, M.; PEDUZZI, M. Articulação entre as dimensões gerencial e assistencial do processo de trabalho do enfermeiro. Texto Contexto - enferm. [Online]. v. 18, n. 2, p. 258-265, 2009. Disponível em: <http://www.scielo.br/pdf/tce/v18n2/08> . Acesso em: 15 maio 2013.

\section{UNIVERSIDADE FEDERAL DO PARANÁ (UFPR).}

Hospital de Clínicas. Histórico. Disponível em: <http:// www.hc.ufpr.br/?q=content/historia-do-hc $>$. Acesso em: 20 ago. 2012.

KARINO, M. E. As causas de morte dos enfermeiros: uma revisão sistemática. 2012. 167 f. Tese (Doutorado em Ciências) - Universidade de São Paulo, Escola de Enfermagem da Universidade de São Paulo, São Paulo, 2012.

KURCGANT, P. Gerenciamento em Enfermagem. 2 ed. Rio De Janeiro: Guanabara Koogan, 2010, 208 p.

TEIXEIRA, R. C.; MANTOVANI, M. F. Enfermeiros com doença crônica: as relações com o adoecimento, a prevenção e o processo de trabalho. Rev. Esc. Enferm. Usp [Online].v. 43, n. 2, p. 415-421, 2009. Disponível em: <http://www.scielo.br/scielo.php?script=sci_artte xt\&pid=S0080-62342009000200022 >. Acesso em: 20 ago. de 2012.

TOBAR, F., YALOUR, M. R. Como fazer teses em saúde pública: conselhos e ideias para formatar projetos e redigir teses e informes de pesquisas. Rio De Janeiro: Fiocruz, 2001.

Recebido para publicação em junho de 2014

Versão final em janeiro de 2015

Conflito de interesse: inexistente

Suporte financeiro: não houve 